\title{
Spatial and Temporal Induction of Cell Death, Defense Genes, and Accumulation of Salicylic Acid in Tobacco Leaves Reacting Hypersensitively to a Fungal Glycoprotein Elicitor
}

\author{
Stephan Dorey, Fabienne Baillieul, Marie-Agnès Pierrel, Patrick Saindrenan, Bernard Fritig, and \\ Serge Kauffmann \\ Institut de Biologie Moléculaire des Plantes du C.N.R.S., Université Louis Pasteur. 12, rue du Général \\ Zimmer, 67084 Strasbourg Cedex, France \\ Received 19 December 1996. Accepted 11 March 1997.
}

We have analyzed the spatial and temporal expression of defense responses induced in attached tobacco leaves treated with a Phytophthora megasperma glycoprotein that was previously shown to be an efficient elicitor of the hypersensitive reaction. The infiltrated tissue (zone 1), the surrounding tissue (zone 2), which is $5 \mathrm{~mm}$ in width, and tissue at a distance $>2 \mathrm{~cm}$ from zone 2 (zone 3 ) were analyzed separately. Cell death occurred only in zone 1 and was completed by $14 \mathrm{~h}$. Defense gene expression was induced in zones 1 and 2 with striking differential patterns, but not in zone 3 . There was a rapid ( 1 to $4 \mathrm{~h}$ ) induction of genes of the phenylpropanoid, salicylic acid, and sesquiterpenoid pathways in zones 1 and 2 . However, it was strong and transient in the former and of lesser extent but sustained in the latter. High amounts of scopoletin, a phenylpropanoid metabolite, were found synthesized in zone 2. Pathogenesis-related (PR) transcripts and the corresponding $P R$ proteins accumulated in high amounts in zone 2 rather late after the treatment $(24 \mathrm{~h})$. Salicylic acid was synthesized in both zone 1 and zone 2. Using a radioactively labeled elicitor, we demonstrated that the elicitor remained strictly localized to zone 1 . The results provide strong evidence that an endogenous cell-to-cell signaling mechanism was triggered and occurred between the elicitor-treated cells (zone 1) and the surrounding cells (zone 2), where it induces strong defense responses without cell death.

Additional keywords: local acquired resistance.

The hypersensitive reaction (HR) is a mechanism by which efficient disease resistance to pathogens is induced in plants (Klement 1982). Phenotypically, HR results in plant cell death that occurs at the site of pathogen penetration. This phenomenon of cell death is reminiscent of programmed cell death de-

Corresponding author: Serge Kauffmann;

Phone: 33-(0)3 884172 71; Fax: 33-(0)3 886144 42;

E-mail: kauffmann@medoc.u-strasbg.fr

Stephan Dorey and Fabienne Baillieul contributed equally to the work in this paper and should be considered joint first authors. scribed in animal systems (Jones and Dangl 1996). It is accompanied by a large set of defense responses that are also induced (Atkinson 1993). Secondary metabolic pathways are stimulated, such as the sesquiterpenoid (Stoessl et al. 1976) and phenylpropanoid (Legrand 1983) pathways, that produce phytoalexins and phenolics, some of which are incorporated into the cell wall for its reinforcement (Dixon and Lamb 1990). Furthermore, a broad range of defense-related proteins, the pathogenesis-related (PR) proteins, are synthesized in high amounts and most of them display antimicrobial activity (Stintzi et al. 1993b). Many of these defense responses have been shown to result from transcriptional activation of defense genes (reviewed by Lamb et al. 1989).

Several reports have shown that expression of defense responses occurs in a narrow ring of cells surrounding necrotic infection sites (reviewed by Kombrink and Somssich 1995). However, it is not clear whether these induced defense responses also occur within the cells undergoing hypersensitive cell death. It is also not established whether defense responses found in cells surrounding an HR lesion are regulated by pathogen or plant signals or both. For instance, in tobacco reacting hypersensitively to tobacco mosaic virus (TMV), the cells immediately beyond the necrotic lesion contain some infectious virus particles (Konate et al. 1982) that may be the source of elicitor molecules inducing the defense responses. This finding also suggests that hypersensitive cell death is necessary but not sufficient to restrict pathogen spread and that the defense responses induced in the sharp zone surrounding the HR cells might also be essential. HR cells could be another source of signal molecules regulating defense responses in the tissue next to the infection site (Collinge and Slusarenko 1987).

The strong stimulation of defense responses in cells surrounding the HR lesion is likely to be related to the phenomenon of local acquired resistance (LAR) described by Ross (1961a) with the TMV-tobacco hypersensitive interaction. In this study, LAR operated in a 1- to 2-mm zone of tissue surrounding each local lesion, and provided immunity to challenge virus inoculation. Ross (1961b) also reported that systemic acquired resistance (SAR) occurred beyond the LAR zone. In fact, SAR developed on the primary infected leaf and 
throughout the plant. LAR provided a much higher level of resistance than SAR.

There is compelling evidence that salicylic acid (SA) is a key signal molecule regulating local defense responses and SAR (for a review see Klessig and Malamy 1994). The most convincing data came from experiments with transgenic tobacco plants that catabolize SA to catechol. Such plants, which fail to accumulate SA, show increased susceptibility to pathogens (Delaney et al. 1994) and do not establish SAR (Gaffney et al. 1993).

We have shown previously that a Phytophthora megasper$m a$ glycoprotein was able to induce an HR upon infiltration into tobacco leaves (Baillieul et al. 1995). Necrosis occurred several hours after the treatment. Typical defense-related genes such as PAL (phenylalanine ammonia-lyase), OMT (odiphenol-O-methyltransferases), and HMGR (3-hydroxy-3methylglutaryl CoA reductase) were rapidly activated after elicitor treatment. The time course of SA production was slightly shifted compared with PAL gene expression, and PR mRNAs and proteins accumulated after visible necrosis had appeared. SAR to challenge TMV infection was also induced.

Here, we describe the spatial and temporal induction of these responses to the HR-inducing elicitor, and we have included in this study the kinetics of cell death and the pattern of accumulation of scopoletin, a typical defense metabolite (Ahl-Goy et al. 1993; Fritig et al. 1972) issuing from the phenylpropanoid pathway (Fritig et al. 1970). We have ana- lyzed separately (i) the tissue infiltrated with the purified glycoprotein, (ii) the surrounding fluorescent tissue, and (iii) the symptomless tissue at a distance from the lesion. We show that the glycoprotein remained strictly localized to the infiltrated tissue, and that the expression pattern of the different defense genes differed strikingly between the different tissues analyzed. The results suggest that an efficient endogenous cell-to-cell signaling mechanism was triggered in cells perceiving the exogenous microbial signal and induced strong defense responses without cell death in neighboring cells.

\section{RESULTS}

\section{Kinetics of cell death induced by the glycoprotein infiltrated into tobacco leaves.}

Infiltration into tobacco leaves of $50 \mathrm{nM}$ purified glycoprotein induced necrosis localized to the treated tissue (called zone 1) that appeared reproducibly 18 to $24 \mathrm{~h}$ after treatment (Fig. 1A). The arrow in Figure 1A shows the marker line drawn immediately after the infiltration, indicating the limit of liquid spread into the tissue. Under such conditions, we never observed necrosis beyond the infiltration site. A bright blue autofluorescence became visible under UV light, $24 \mathrm{~h}$ after treatment, in a ring of cells (called zone 2) surrounding zone 1 (Fig. 1B). The tissue beyond the fluorescent zone, called zone 3 , remained symptomless. Considering these observations, zone 1 will be the infiltrated tissue, zone 2 will be the tissue 5
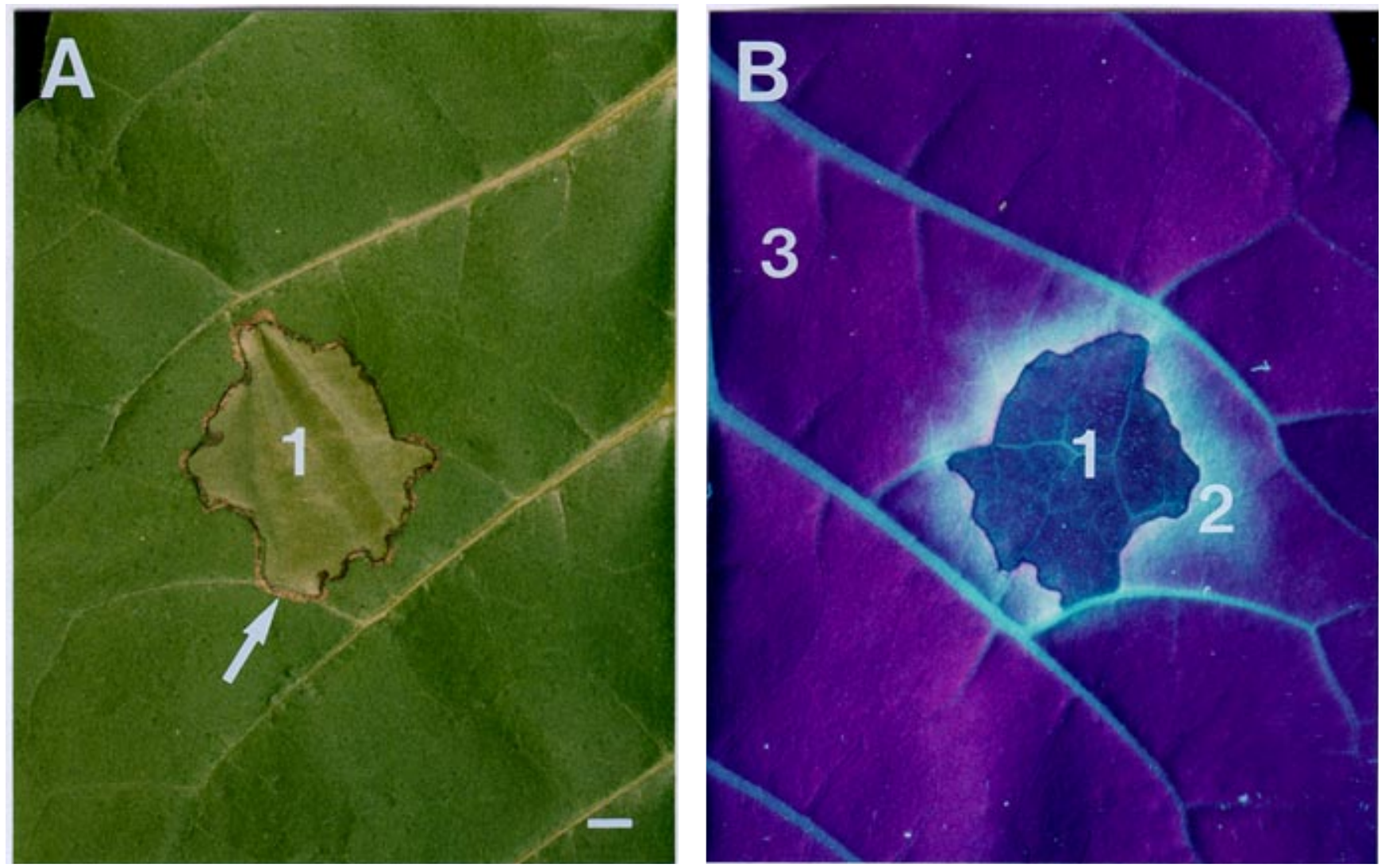

Fig. 1. Sampling zones after infiltration into a tobacco leaf of the Phytophthora megasperma glycoprotein. Symptoms were photographed 2 days after treatment with $50 \mathrm{nM}$ glycoprotein under (A) white light or (B) UV light. A, Arrow indicates the marker line drawn immediately after the infiltration defining the limit of liquid spread. Numbers indicate the different zones of sampling: 1, the infiltrated tissue (zone 1); 2, the surrounding tissue, which is $5 \mathrm{~mm}$ in width (zone 2); 3 , tissue at a distance $>2 \mathrm{~cm}$ from zone 2 (zone 3$) . \mathrm{Bar}=0.5 \mathrm{~cm}$. 
$\mathrm{mm}$ in width just beyond the marker line, and zone 3 will be tissue at a distance $>2 \mathrm{~cm}$ from the external limit of zone 2 .

Visual inspection of the elicitor-treated tissue cannot provide clear-cut information about the kinetics of cell death. Thus, we monitored cell death with the Evans blue leaf disk assay described by Baker and Mock (1994) since it has been shown to provide a reliable measurement of cell death in tissue. The glycoprotein-treated, zone 1 tissue rapidly accumulated the vital dye (Fig. 2A, closed symbols). A significant and reproducible uptake was already detected $3 \mathrm{~h}$ after the treatment, reached a maximum at $14 \mathrm{~h}$, and then dropped to zero at $24 \mathrm{~h}$. This type of kinetics was surprising since it did not correlate with the visible appearance of necrosis. Baker and Mock (1994) have reported that the dye was no longer retained when tissue had disintegrated, i.e., rather late in their procedure of HR induction on tobacco leaves. In our system, the loss of dye staining correlated well with the appearance of the necrotic symptoms. These results suggested that by $14 \mathrm{~h}$ all cells of the elicitor-treated, zone 1 tissue had died, and that necrotic symptoms corresponded in fact to disrupted cells. The infiltration procedure itself did not induce cell death since zone 1 tissue infiltrated with water (Fig. 2A, open symbols) did not take up Evans blue.

We have also tested whether the tissue from zone 2 surrounding an elicitor-treated zone 1 contained a significant proportion of dead cells although it remained symptomless (observations were made up to 15 days after treatment). Sev-

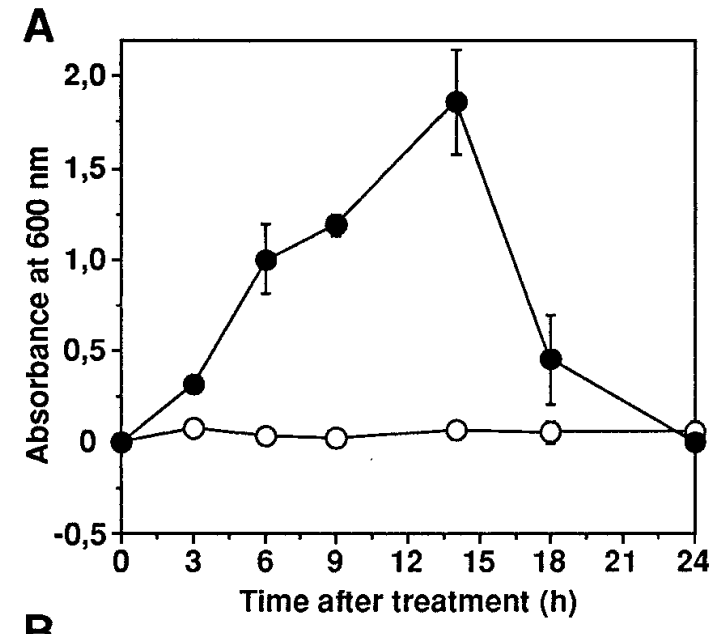

$B$

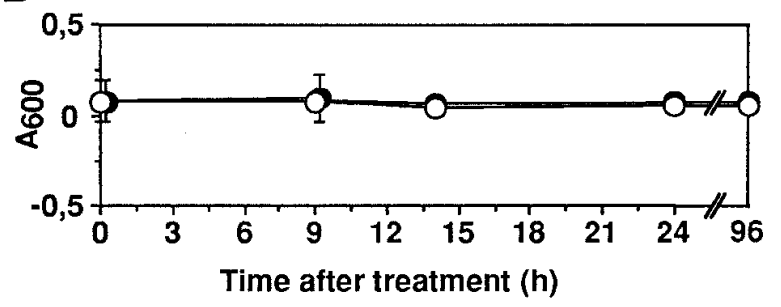

Fig. 2. Evaluation of cell death by monitoring the uptake of Evans blue by elicitor-treated tobacco leaves. Leaves were infiltrated with $50 \mathrm{nM}$ glycoprotein (closed circles) and water as a control (open circles). Leaf disks were punched out from leaves at the indicated times from the (A) zone 1 and (B) zone 2 tissue. Uptake of vital dye was quantified by spectrophotometry. Four disks from 4 treated tissues were used for each assay. Each time point represents the mean of two independent experiments and indicates the calculated standard deviation. eral assays revealed that tissues surrounding either glycoprotein- or water-treated, zone 1 tissues did not retain the dye (Fig. 2B). Therefore, no cell death occurred in zone 2. No dye uptake was detected in tissues of zone 3 as well (data not shown).

\section{Expression of defense genes.}

We first analyzed the expression of defense genes in zone 1 and zone 2 (Fig. 3). Defense-related mRNAs accumulated in the positive HR control consisting of leaves reacting hypersensitively to TMV infection (lane HR), whereas they remained undetectable in nontreated plants (lane NT). In this experiment, water treatment induced an early and transient expression of HMGR and PR- 6 genes and a late expression of PAL gene in zone 1, and an unexpected late expression of PR6 gene in zone 2. The expression of the other genes remained unaffected. It should be noted that another, independent experiment did not reveal PAL and HMGR gene expression in tissue infiltrated with water. This might reflect a variable wounding response depending on the pressure applied during liquid infiltration. The expression pattern of the different defense genes differed strikingly between zones 1 and 2 of elicitor-treated leaves (lanes "elicitor"). PAL, OMT, and HMGR mRNAs accumulated rapidly in zone 1 with a maximum at $14 \mathrm{~h}$, followed by a decrease that correlated with the loss of Evans blue staining. Induced expression of these genes also occurred in zone 2 . Induction was to a lesser extent but was sustained for several days. Low levels of PR-3, -5 , and -6 mRNAs were found in zone 1 , while PR-1 and -8 messengers were almost undetectable. In zone $2, \mathrm{PR}$ mRNAs started to accumulate $18 \mathrm{~h}$ after treatment, with a maximum around 38 h. Slight different patterns of PR gene expression were revealed. Overall, these results indicated that a strong expression of PR genes occurred in zone 2 several hours after the death of cells of zone 1, whereas PAL, OMT, and HMGR genes were strongly expressed in zone 1 before the death of all cells. This was observed in several independent experiments. These findings on spatio-temporal regulation are consistent with our previous results (Baillieul et al. 1995), which differentiated early expressed genes, referred to as the class I genes (PAL, OMT, and HMGR genes), from late expressed genes, the class II genes (PR genes).

Examination of various plant-pathogen interactions, including the HR of tobacco to TMV, revealed a sharp demarcation between cells expressing defense responses and unaffected cells (reviewed by Kombrink and Somssich 1995). Therefore, we further analyzed whether expression of class I and class II defense genes would be induced in zone 3 at a time when these genes exhibit strong induction in zone 2, i.e., $48 \mathrm{~h}$, and before the induction of SAR, which occurs only several days later (Baillieul et al. 1995). No accumulation of class I and class II mRNAs was measured by Northern (RNA) analysis of zone 3 tissue of elicitor-infiltrated leaves $48 \mathrm{~h}$ after treatment (data not shown).

\section{Changes in PR proteins and scopoletin.}

Accumulation of PR proteins was analyzed by immunoblotting (Fig. 4). In control nontreated or water-infiltrated leaves, no PR proteins were detected except low amounts of PR-2 and PR-3. They probably correspond to the basic isoforms that are known to be constitutively produced in leaves 
(Heitz et al. 1994). PR proteins accumulated in high amounts in zone 2 tissues of elicitor-treated leaves. In zone 1, no detectable levels of PR proteins were found, even for PR-3, PR5, and PR-6, whose mRNA levels were transiently increased in this zone (Fig. 3). An explanation could be that PR mRNAs started to accumulate in cells of zone 1, but because of cell death the translation did not have time to proceed and yield detectable amounts of PR proteins.

PAL and OMT genes encode enzymes that are among those involved in the synthesis of scopoletin. We, thus, measured by high-performance liquid chromatography (HPLC) the accumulation of scopoletin, which displays a bright blue fluorescence under UV light (Fritig et al. 1972). Amounts of scopoletin found in control leaves, i.e., nontreated leaves (corresponding to the zero time point) and leaves treated with water (Fig. 5, open circles), were about $250 \mathrm{ng}$ per $\mathrm{g}$ of fresh weight and remained at this level during the course of the experiment. A small increase in scopoletin was measured in zone 1 tissue treated with the glycoprotein (Fig. 5A, closed circles), whereas a strong accumulation occurred in zone 2 (Fig. 5B, closed circles). For zone 2 , an increase in the amounts was reproducibly measured as soon as $6 \mathrm{~h}$ after treatment, and reached a 10 -fold stimulation by $24 \mathrm{~h}$. The fact that only low amounts of scopoletin were found in zone 1, although PAL and OMT genes were strongly stimulated, could result from the high sensitivity of scopoletin to oxidation (Root et al. 1975) that is likely to occur in the elicitortreated, zone 1 tissue.

\section{Analysis of salicylic acid.}

SA accumulation was analyzed in tissue of zones 1 and 2 collected from elicitor-treated and water-treated leaves. Figure 6 shows the results of a typical experiment. Zone 1 and 2 tis- sues of water-infiltrated leaves did not accumulate SA (open circles). Increasing amounts of SA were measured in glycoprotein-treated, zone 1 tissue, with a maximum at $14 \mathrm{~h}$ followed by a decrease (Fig. 6A, closed circles). At $24 \mathrm{~h}$ after the treatment, the elicitor-treated, zone 1 tissue was fully necrotized; thus, no tissue was collected after that time. It is noteworthy that this decrease in SA levels occurred at a time when all cells in zone 1 were dead (Fig. 2A). Thus, due to cell death, SA could either be degraded at the site of production or diffuse to zone 2. SA also accumulated in this latter zone but with different kinetics (Fig. 6B, closed circles). SA measurements were made up to $48 \mathrm{~h}$ after the treatment since this tissue did not show any sign of necrosis or cell death (see Fig. 2B). The increase was slower but sustained up to the last time of sampling. This lack of decrease in SA levels contrasted with the situation in zone 1 and suggested that SA was not degraded in zone 2 or that the appearance of new SA occurred at rates higher than or at least equivalent to those of its degradation.

To gain further insight into the origin of SA found in zone 2 of elicitor-treated leaves, we inhibited SA synthesis in zone 1 tissue with $250 \mu \mathrm{M}$ AOPP ( $\alpha$-aminooxy- $\beta$-phenylpropionate), a potent competitive inhibitor of PAL activity (Massala et al. 1987). Infiltration of the inhibitor alone did not result in SA accumulation (Fig. 6A and B, open triangles). Co-infiltration of AOPP and the glycoprotein clearly reduced SA accumulation in zone 1 (Fig. 6A, closed triangles) without affecting the time course of SA increase and levels in zone 2 (Fig. 6B, closed triangles). Thus, most of the SA found in zone 2 resulted from de novo synthesis. Nevertheless, we cannot rule out the possibility that low amounts of SA could diffuse from zone 1 to zone 2, namely because of cell disruption occurring in zone 1.

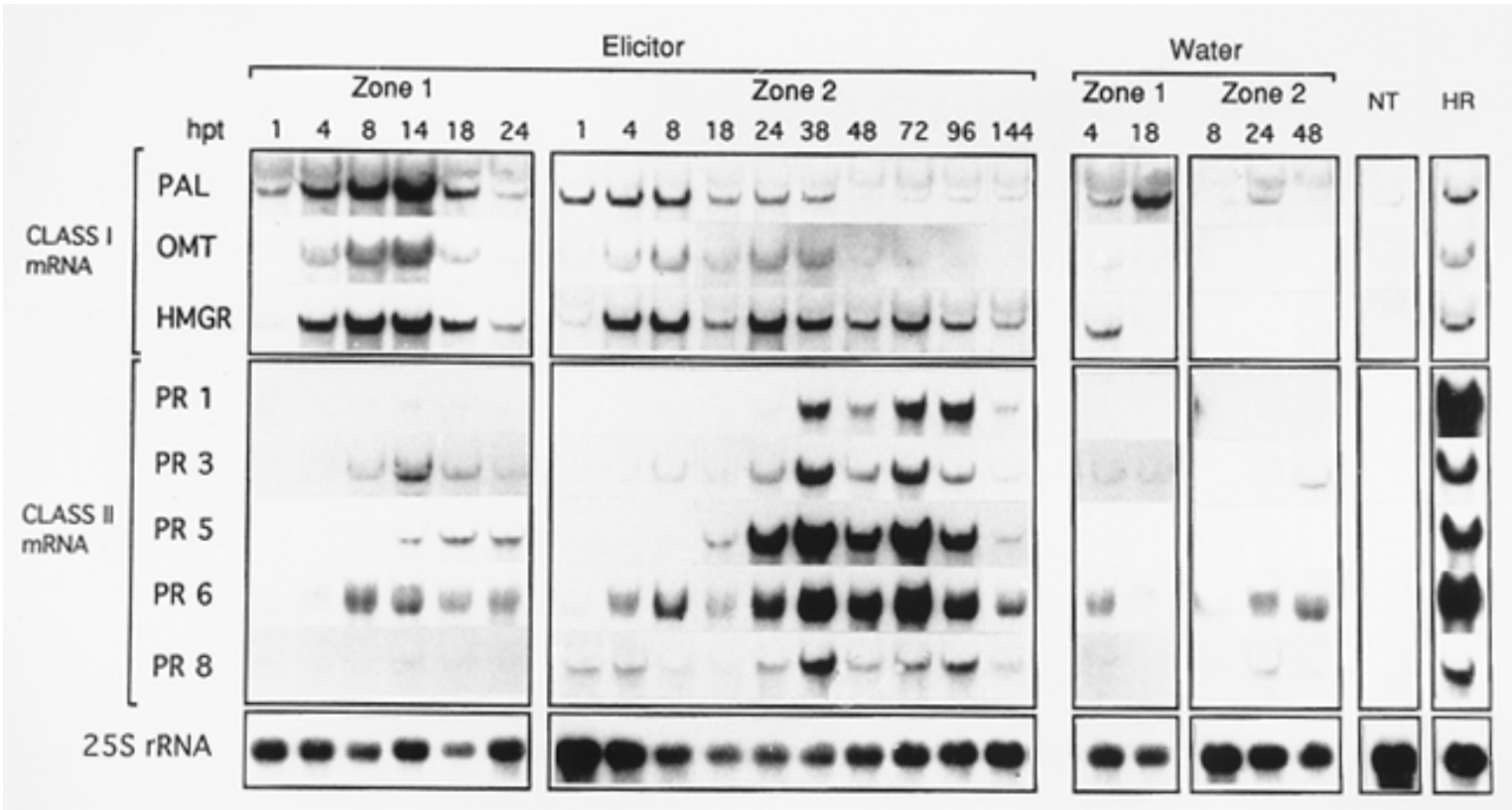

Fig. 3. Analysis of defense-related mRNA in elicitor-treated tobacco leaves. Leaves were infiltrated with 50 nM glycoprotein (lanes "elicitor"), water (lanes "water"), or inoculated with tobacco mosaic virus (TMV) (lane HR). Total RNA was extracted at different times (hpt: hours post-treatment), from the zone 1 and zone 2 tissue. Total RNA was also extracted from nontreated plants (lane NT). RNA from TMV-infected tissue was isolated 2 and 5 days after virus inoculation to probe for class I and class II cDNAs, respectively. Twelve micrograms of RNA was electrophoresed and blotted onto a nylon membrane. The blot was hybridized with the different ${ }^{32} \mathrm{P}$-labeled cDNA probes as indicated. 


\section{Localization of the glycoprotein.}

The above results indicate that cells surrounding the tissue treated with the HR-inducing glycoprotein were stimulated to produce typical defense responses such as the production of defense-related proteins, scopoletin, and SA. Thus, a signal diffusing from zone 1 to zone 2 was likely to occur and to regulate the induction of the defense responses in zone 2, since only zone 1 had been infiltrated with the glycoprotein.

The diffusing signal could be the glycoprotein itself. To address this question, we studied the localization of labeled elicitor after infiltration. After labeling with ${ }^{125}$ I the glycoprotein retained full biological activity. Figure 7 illustrates three independent experiments aimed to analyze (Fig. 7A) and quantify (Fig. 7B) the radioactivity found in proteins, and to quantify the total radioactivity present in zone 1 and 2 tissues in the course of the experiment (Fig. 7C). Total protein extracts were made from zone 1 and 2 of leaves infiltrated with the labeled elicitor and submitted to sodium dodecyl sulfatepolyacrylamide gel electrophoresis (SDS-PAGE). The radioactivity was revealed by autoradiography of the gel (Fig. 7A). A strong radioactive signal was found in lane 1 loaded with proteins from zone 1. Its electrophoretic mobility was the same as that of labeled glycoprotein run as a control (lane E). No radioactive signal appeared in lane 2 loaded with proteins from zone 2, whatever the time of sampling (tested until $48 \mathrm{~h}$ after infiltration), and no radioactivity could be detected in lane 2 when the gel was analyzed by photostimulated luminescence.

For the second experiment (Fig. 7B), the concentration of the infiltrated, labeled glycoprotein was raised to $175 \mathrm{nM}$ to

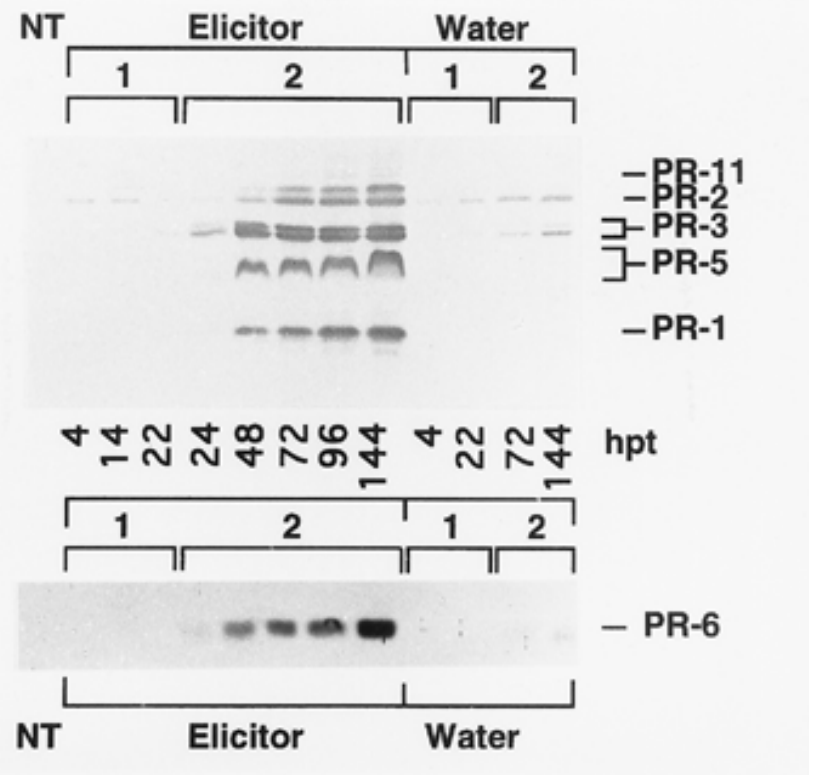

Fig. 4. Analysis of pathogenesis-related (PR) proteins in elicitor-treated tobacco leaves. Leaves were infiltrated with $50 \mathrm{nM}$ glycoprotein (lanes "elicitor") and water (lanes "water"). PR proteins were extracted at different times after treatment (hpt: hours post-treatment) from nontreated plants (lane NT), from the zone 1 and zone 2 tissue. Protein extracts were electrophoresed under denaturing conditions. After transfer onto nitrocellulose, immunodetection was performed with a mixture of antibodies raised against PR-1, PR-2, PR-3, PR-5, and PR-11 proteins, and on a separate blot with anti-PR-6 antibodies increase the sensitivity of the detection. Under such conditions, necrosis was still strictly localized to the infiltrated tissue. When the radioactivity present in the protein extracts was quantified by $\gamma$-counting, the label in proteins of zone $1 \mathrm{de}$ creased rapidly after infiltration and no label was found in zone 2. Such decrease could be explained by degradation or insolubilization of the elicitor, the latter resulting in a loss of elicitor extractability. If degradation would have occurred, labeled and unlabeled elicitor fragments could then diffuse. Such small fragments would be lost during the preparation of the protein extract, which included an ultrafiltration step (cut off $10,000 \mathrm{Da}$ ).

To test whether labeled elicitor fragments were present in zone 2 tissue, we measured the total radioactivity present in whole tissue (Fig. 7C). $\gamma$-Counting allows quantification of the radioactivity present in tissues without the need of an extraction step. In other words, in this type of assay, the measured radioactivity accounted for both extractable and non-extractable labeled protein, as either intact or degraded elicitor. A constant level of radioactivity was found in zone 1 and no radioactivity was measured in zone 2 whatever the sampling time between 0 and $48 \mathrm{~h}$. Thus, if it is possible that both la-
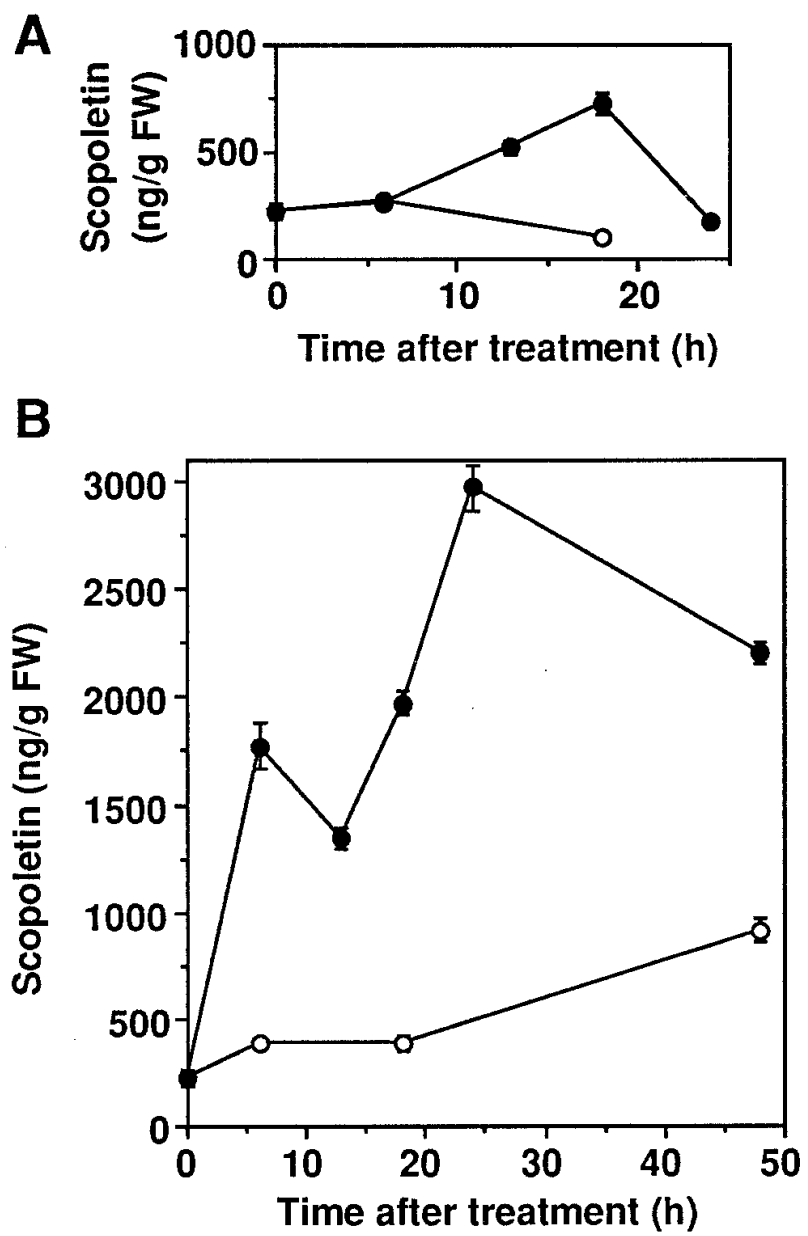

Fig. 5. Analysis of scopoletin in elicitor-treated tobacco leaves. Leaves were infiltrated with $50 \mathrm{nM}$ glycoprotein (closed circles), and water (open circles). Scopoletin was extracted from the (A) zone 1 and (B) zone 2 tissue, and analyzed by high-performance liquid chromatography. Analysis was performed in duplicate. The zero time point corresponds to scopoletin found in nontreated plants. 
beled, intact elicitor and elicitor fragments were present in zone 1 , neither of them had diffused to zone 2 .

Taken together, the results provided good direct evidence for a strict localization of the glycoprotein to the infiltrated tissue. We concluded that induction of strong defense responses in cells surrounding the glycoprotein-treated, zone 1 tissue was triggered by one or several other signals, which are necessarily of plant origin.

\section{DISCUSSION}

The aim of this study was to analyze the spatial and temporal sequence of different defense responses induced in tobacco treated with a pure molecule capable of eliciting an HR. Infil-

A
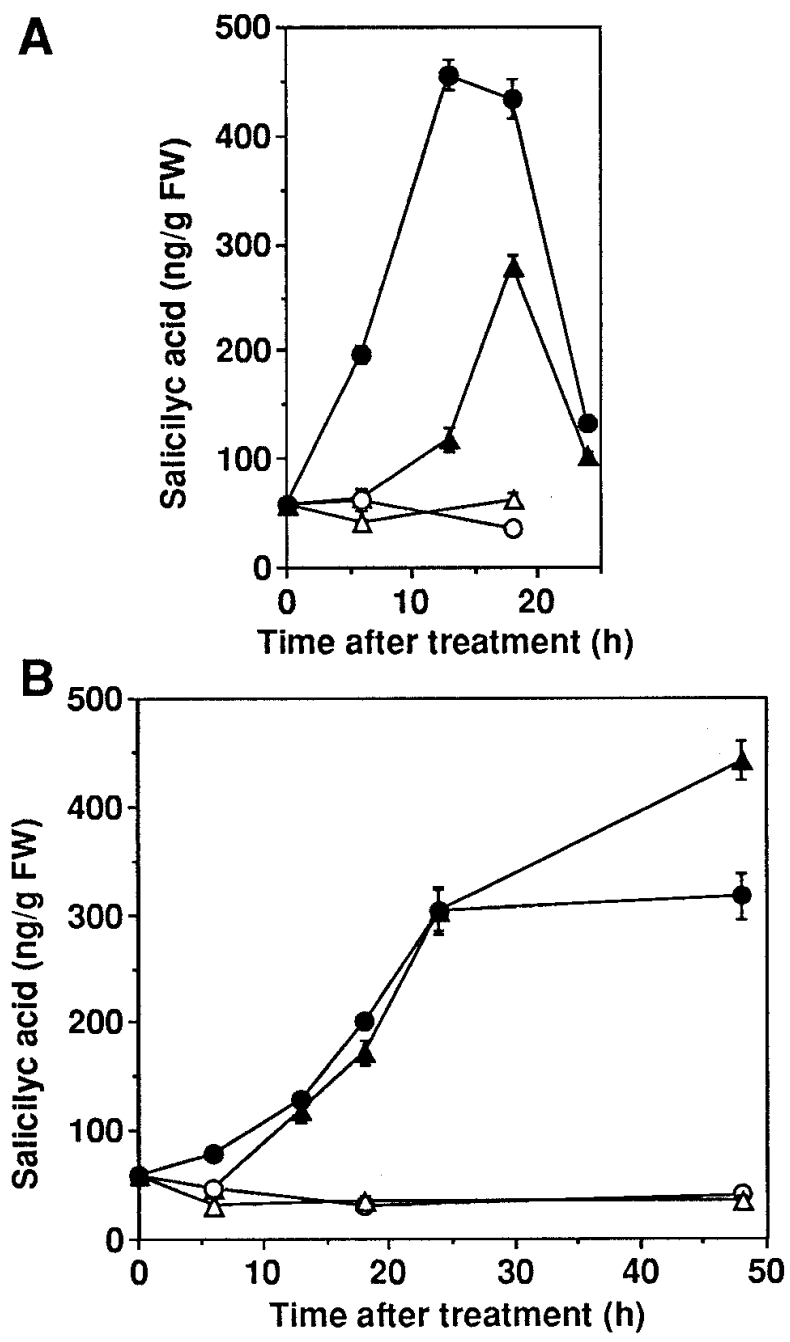

Fig. 6. Analysis of salicylic acid (SA) in tobacco leaves infiltrated with the elicitor in the presence or absence of an inhibitor of phenylalanine ammonia-lyase (PAL) activity. Glycoprotein $(50 \mathrm{nM})$ was infiltrated into leaves in the absence (closed circles) or presence (closed triangles) of $250 \mu \mathrm{M} \alpha$-aminooxy- $\beta$-phenylpropionate (AOPP), a competitive inhibitor of PAL activity. Controls consisted of tissue infiltrated with water (open circles) and AOPP alone (open triangles). SA was extracted from the (A) zone 1 and (B) zone 2 tissue, and analyzed by high-performance liquid chromatography. Analysis was performed in duplicate. The zero time point corresponds to SA found in nontreated plants. tration of the elicitor into leaves still attached to the plant allows an accurate control of the leaf tissue area in contact with the elicitor and is expected to provide a synchronous challenge to a population of plant cells. The procedure also avoids the possible occurrence of multiple exogenous signals due to pathogen growth or to application of a crude elicitor preparation. The major finding in this study is that cells of a narrow zone surrounding an elicitor-treated tissue accumulated high
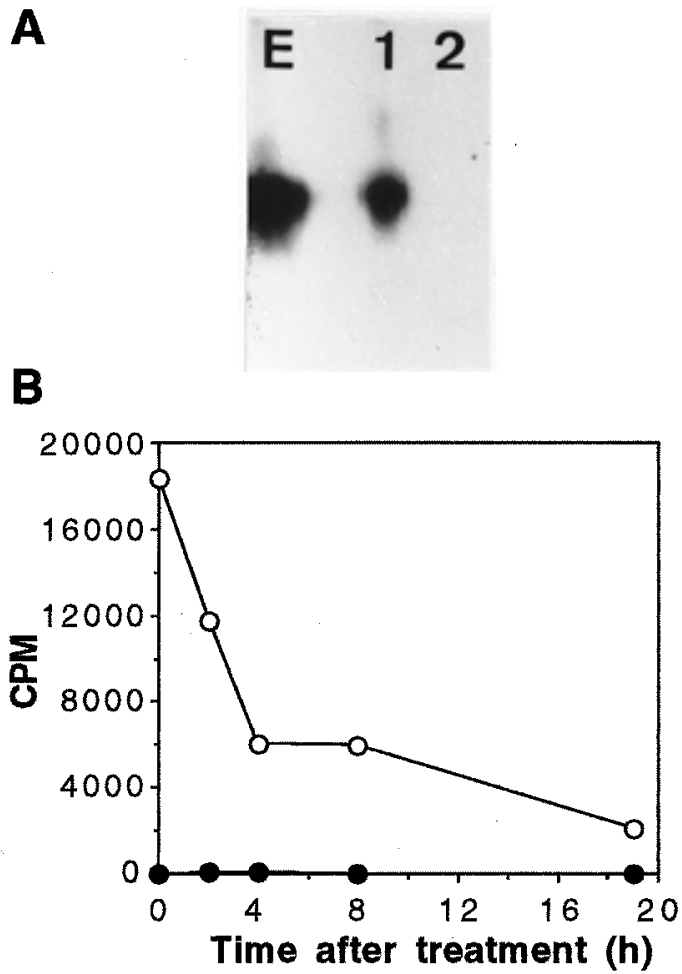

C

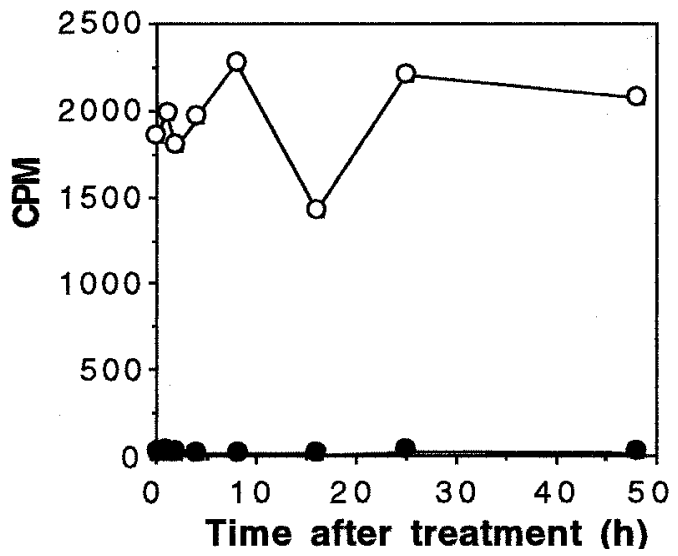

Fig. 7. Localization of labeled elicitor after infiltration into tobacco leaves. After infiltration of ${ }^{125} \mathrm{I}$-labeled glycoprotein into tobacco leaves, zone 1 and 2 tissues were collected after various times of incubation. A, $50 \mathrm{nM}$ glycoprotein was infiltrated and proteins extracted and submitted to sodium dodecyl sulfate-polyacrylamide gel electrophoresis followed by autoradiography of the gel. Lane E was loaded with the radiolabeled glycoprotein as control. Lanes 1 and 2 were loaded with the protein extract made from zones 1 and 2, respectively. B, Glycoprotein (175 nM) was infiltrated and radioactivity found in the protein extracts made from zone 1 (open circles) and zone 2 (closed circles) was quantified by $\gamma$ counting (CPM: counts per minute). C, Glycoprotein (50 nM) was infiltrated and total radioactivity found in leaf tissue from zone 1 (open circles) and zone 2 (closed circles) was quantified by $\gamma$-counting. 
amounts of defense metabolites and proteins, although the elicitor remained strictly localized to the infiltrated zone. An endogenous cell-to-cell signaling should, therefore, occur to account for the observed strong defense response at a distance from the application of an exogenous primary signal.

Such a result was obtained through consideration and separate analysis of three types of tissue in leaves treated with 50 nM glycoprotein: (i) the infiltrated tissue (zone 1), that accumulated defense-related transcripts and SA, and then became necrotic; (ii) the surrounding tissue (zone 2) that accumulated all of the investigated defense-related transcripts, PR proteins, and fluorescent metabolites like scopoletin and SA, and in which cell death was neither visually nor biochemically detected at any time; and (iii) the tissue beyond zone 2 (called zone 3) that remained unaffected in the timing conditions of this study. The demarcation of treated to surrounding tissue resulted from visual observation of the spread of liquid into the tissue and subsequent marking. The fact that the boundary between necrotic and non-necrotic tissue coincided with the latter marking was an important prerequisite for the study. It indicated a clear demarcation between the infiltrated, zone 1 tissue and nontreated tissue. Another demarcation occurred between tissue showing fluorescence under UV light (zone 2) and tissue remaining symptomless (zone 3 ). This latter observation correlated well with other observations during various plant-pathogen interactions that also pointed to a sharp demarcation between cells expressing defense responses and unaffected cells (Kombrink and Somssich 1995).

The increase in cell death was almost parallel to the increase in class I transcript and SA accumulation in the elicitor-treated, zone 1 tissue. Cell death was clearly observed as early as $3 \mathrm{~h}$ after treatment. Elicitins are known to induce HR in tobacco (Blein et al. 1991; Ricci et al. 1989) and have been shown to display some serological relationships with our glycoprotein (Baillieul et al. 1996). Apoptosis was observed at the onset of the HR in suspension-cultured tobacco cells treated with elicitins (Levine et al. 1996). Hence, the rapid onset of cell death after glycoprotein treatment could also be of apoptotic nature. The visible necrosis covering the entire infiltrated tissue by 18 to $24 \mathrm{~h}$ correlated well with the loss of vital dye staining after 14 $\mathrm{h}$ that in turn was associated with the disintegration of dead cells (Baker and Mock 1994). The decrease in mRNA levels could therefore result from degradation. A similar explanation could apply for the drop of SA levels.

On the other hand, a strong metabolic stimulation was induced in the narrow ring of cells showing bright blue fluorescence under UV light. The fluorescent compounds are most probably phenylpropanoids and their derivatives such as the coumarin scopoletin that was shown previously to accumulate in high amounts in tobacco leaves reacting hypersensitively to TMV (Fritig et al. 1972), and to be a significant marker of disease resistance in the hybrid Nicotiana glutinosa $\times N$. debneyi (Ahl-Goy et al. 1993). The expression of PAL and OMT genes and the accumulation of scopoletin indicate that the phenylpropanoid pathway was stimulated in zone 2 surrounding elicitor-infiltrated tissue. The accumulation of HMGR transcripts suggests that another secondary pathway, the sesquiterpenoid pathway leading to the typical phytoalexins of Solanaceae such as capsidiol (Stoessl et al. 1976), was also activated in this zone 2 . PR genes were strongly induced in this zone, and the corresponding proteins accumulated in high amounts. Overall, these results show that plant cells surrounding an HR lesion are strongly stimulated and produce a large set of defense responses without being destined to die.

The occurrence and the localization of such strong defense responses found in the zone 2 tissue surrounding the typical HR lesion could be part of the LAR phenomenon (Ross 1961a). Indeed, according to Ross, two main characteristics differentiate LAR from SAR: their tissue localization, and the level of resistance they provide. LAR concerns only a small number of cells surrounding an HR lesion and provides immunity to challenge infection (no new lesion develops), while SAR occurs beyond the LAR tissue and provides a higher level of resistance to challenge pathogen inoculation (new lesions develop, but are smaller in size). The presence of high levels of defense proteins and metabolites in zone 2 could provide immunity to challenge infection. Whether TMV inoculation would result in the formation of HR lesions in zone 2 surrounding elicitor-treated tissue is currently being tested. Recently, other authors, referring also to Ross's work, defined LAR as acquired resistance arising in symptomless tissue surrounding HR lesions, typically within the same plant leaf, thus corresponding to zone $2+3$ in our system (Malamy et al. 1996; Mur et al. 1996). They defined SAR as the acquired resistance occurring in uninoculated leaves. In our experimental system, expression of the defense genes was not stimulated in zone 3 within the 0 - to 48 -h period after the elicitor treatment that is before the induction of SAR (Baillieul et al. 1995). We did not analyze the expression of SAR genes in zone 3 when SAR is induced, which occurs several days later. It should be noted that PR transcripts were found in tobacco SAR tissues only 6 days after inoculation with TMV (Ward et al. 1991). Recombination of the data is consistent with zone 3 corresponding to the one that will develop SAR (Baillieul et al. 1995).

SA was found in both zone 1 and 2 tissues of elicitorinfiltrated leaves. This finding is consistent with its suggested role as an important signal involved in local defense responses (Delaney et al. 1994). Levels of SA in our system were lower than those measured in tobacco leaves reacting hypersensitively to TMV (Malamy et al. 1990). This can be explained in terms of a single and transient stimulation after application of the glycoprotein whereas elicitation during the HR to TMV lasts for a longer time since spread of the virus and necrotization proceed for at least 1 week. However, SA levels in tobacco similar to those reported here were associated with the expression of PR proteins (Yalpani et al. 1991). Furthermore, accumulation of SA in both zone 1 and zone 2 of glycoprotein-treated leaves clearly preceded the stimulation of PR genes. These observations are in agreement with the current view that $\mathrm{SA}$ is a candidate signal for PR gene induction (Bi et al. 1995; Yalpani et al. 1991). The fact that PAL gene expression was followed by SA production, and that treatment with AOPP, a known inhibitor of PAL activity (Massala et al. 1987), led to decreasing amounts of SA in elicited cells, argues in favor of PAL being a key enzyme involved in SA synthesis, as already suggested (Meuwly et al. 1995). The experiments in which AOPP was infiltrated in zone 1 also showed that most SA found in zone 2 resulted from de novo synthesis, and not from the diffusion of SA from zone 1 to zone 2. A similar conclusion could be applied to scopoletin, another metabolite situated farther in the phenylpropanoid 
pathway. Indeed, only a low and transient increase in scopoletin occurred in zone 1 , whereas a strong accumulation was measured in zone 2. Furthermore, the presence of similar amounts of SA in zone 1, destined to necrotize, and in zone 2, showing no sign of necrosis or cell death, suggests that SA does not mediate necrosis in tobacco, as already reported (Keller et al. 1996).

The strict localization to the infiltrated zone of the radiolabeled glycoprotein is clear evidence that an endogenous signaling mechanism accounted for the triggering of the defense responses in cells surrounding the elicitor-treated tissue. The measurements by $\gamma$-counting of the total radioactivity found in leaves and of the radioactivity found specifically in reextracted protein indicated that the ${ }^{125}$ I-labeled glycoprotein was probably insolubilized and/or degraded at the site of application. Elicitor activity due to unlabeled peptides resulting from cleavage of the glycoprotein can be ruled out. Indeed, the specific reduction of disulfide bridges followed by alkylation of the reduced thiol groups was shown to abolish the elicitor activity of the glycoprotein (Baillieul et al. 1995), indicating that the native conformation is essential for the activity. Concerning SA, reports have shown that significant levels were found in the phloem, suggesting that SA is capable of moving throughout the plant (Mölders et al. 1996; Yalpani et al. 1991). Our results do not rule out that very low amounts of SA can diffuse from zone 1 to zone 2, i.e., from cell to cell, which could occur because of cell disruption. The question whether these low amounts of SA could be involved as the initial trigger of the signaling to zone 2 of our system needs further investigation.

Taken together, our results and those from the literature suggest a scenario summarized in Figure 8 . The perception by plant cells of a pathogenic signal inducing an HR leads to the death of those cells corresponding to zone 1 in our experimental system. HR cells express defense genes leading to accumulation of SA, which could regulate PR genes. However, due to the timing of gene expression and cell death, sustained transcription and translation have time to proceed to some extent for early defense genes but not for others, such as PR genes. A similar sequence of defense gene induction and SA production also occurs in a narrow zone (zone 2) of cells surrounding the HR cells. Because cell death is not induced here, the defense gene products can accumulate in high amounts. An endogenous signaling would originate from the HR cells and trigger the strong defense responses found in zone 2: the resulting defense proteins and metabolites would contribute to LAR. This induced signaling could, therefore, be termed the LAR signaling. It is hypothesized that SAR occurs immediately beyond the LAR tissue as observed by Ross (1961b). It is not clear whether LAR and SAR are mediated by different signals or different signal mechanisms. Indeed, a rapid decay of a single signal along the way of translocation could explain the occurrence of LAR and SAR. One may also consider that (i) SAR in tobacco is induced only several days after elicitor treatment (Baillieul et al. 1995) or after TMV inoculation (Ross 1961b), and that (ii) the LAR cells are metabolically stimulated for several days, whereas HR cells die rapidly, leading to collapsed tissue that could dry up the source of signal molecules. Therefore, one can speculate that the LAR cells rather than the HR cells would release the SAR signal. We are currently testing the latter hypothesis.

\section{MATERIALS AND METHODS}

\section{Biological assays.}

Solutions were infiltrated with a syringe equipped with a fine needle into the mesophyll of fully developed leaves of 3month-old tobacco plants ( $N$. tabacum cv. Samsun NN) grown in a glasshouse under controlled conditions. Routinely, 50 to $100 \mu \mathrm{L}$ of solution was applied in order to infiltrate leaf areas of 3 to $4 \mathrm{~cm}^{2}$. The infiltrated tissue (zone 1), the surrounding tissue (zone 2), and the tissue beyond zone 2 (called zone 3 ) were collected as follows. To precisely identify the infiltrated zone, the leaf was illuminated from below immediately after infiltration so that the limit of liquid spread was clearly visible and could be delineated with a felt-tip marker. At different times after treatment, the infiltrated tissue was cut from the leaf with a scalpel along the external limit of the marker line. Then, the tissue, $5 \mathrm{~mm}$ in width, just beyond the marker line (zone 2) was cut out. Zone 3 tissue consisted of leaf disks punched out from the leaf at a distance $>2 \mathrm{~cm}$ from the external limit of zone 2.

Cell death in tobacco leaf tissue was monitored as described by Baker and Mock (1994). The assay was performed with 4 leaf disks ( $8 \mathrm{~mm}$ in diameter) punched out with a cork borer from zones 1 and 2 of leaves of two different plants. Each pair of leaf disks (zone $1+2$ ) originated from a different treated tissue.

\section{Purification of the $P$. megasperma $\mathrm{H} 20$ glycoprotein and protein analysis.}

The glycoprotein was purified from the culture medium of the fungus $P$. megasperma $\mathrm{H} 20$ and quantified as described previously (Baillieul et al. 1995). Extraction of PR proteins from tobacco leaves, and SDS-PAGE and immunoblotting, were performed as in Baillieul et al. (1995). Antisera to probe PR proteins have been raised against PR-1b, PR-2c, PR-3a, PR-5a, PR-11, and PR-6. Extraction of the infiltrated, radiolabeled glycoprotein was performed by grinding 0.5 to $1 \mathrm{~g}$ of leaf tissue with $200 \mathrm{mM} \mathrm{Na}$ phosphate buffer, $\mathrm{pH} \mathrm{6.9,} \mathrm{con-}$ taining $200 \mathrm{mM} \mathrm{NaCl}, 14 \mathrm{mM} \beta$-mercaptoethanol, and $1 \%$ (wt/vol) water-insoluble polyvinylpyrrolidone. After centrifugation at $10,000 \times g$, the supernatant was submitted to ultra-

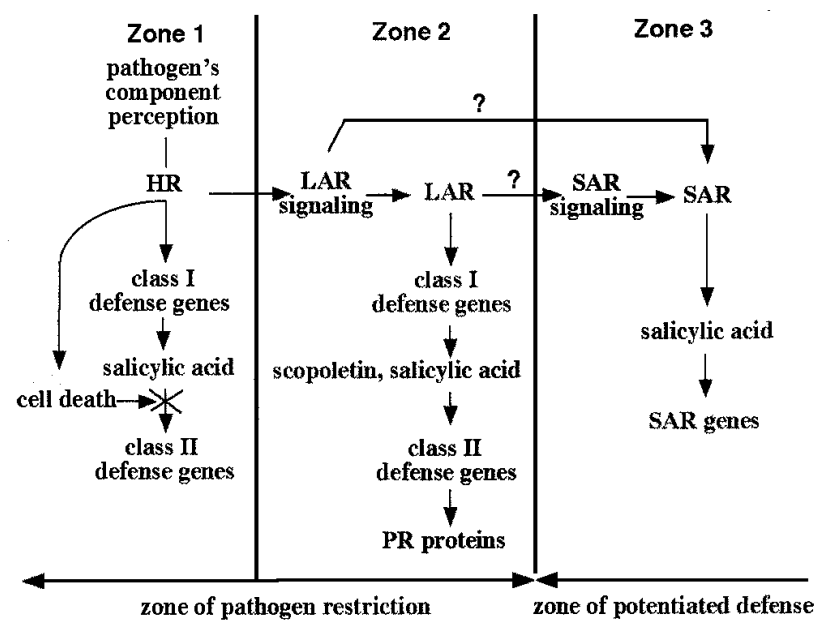

Fig. 8. Proposed spatio-temporal scheme of signaling events and metabolic alterations induced by the glycoprotein elicitor of the hypersensitive reaction. 
filtration with a Centricon 10 (Amicon, Danvers, MA) and the protein extract was washed with $50 \mathrm{mM}$ Tris- $\mathrm{HCl}$ buffer, $\mathrm{pH}$ 7.5. The concentrated protein solution was used for SDSPAGE analysis and $\gamma$-counting of ${ }^{125} \mathrm{I}$.

\section{${ }^{125}$ I labeling of the glycoprotein.}

Labeling of the glycoprotein was performed by L. Legendre (University of Reims, Reims, France). The glycoprotein (100 $\mu \mathrm{g})$ was added to the reaction mixture containing the iodination buffer (100 mM Na phosphate buffer, $\mathrm{pH} 6.8)$, horseradish peroxidase $(100 \mu \mathrm{g}), \mathrm{KI}(100 \mu \mathrm{g}), \mathrm{H}_{2} \mathrm{O}_{2}(0.03 \%)$, and $\mathrm{Na}$ ${ }^{125} \mathrm{I}$ (Amersham, Les Ulis, France, $500 \mu \mathrm{Ci}$ ). The reaction was performed for $1 \mathrm{~h}$ at $37^{\circ} \mathrm{C}$. The reaction mixture containing $\left[{ }^{125} \mathrm{I}\right]$ glycoprotein was loaded onto a G-25 Sephadex column equilibrated with $50 \mathrm{mM}$ Tris- $\mathrm{HCl}$ buffer, $\mathrm{pH}$ 6.8. The labeled glycoprotein was further purified by application onto a QSephadex column and eluted with $200 \mathrm{mM} \mathrm{NaCl}$ in the Tris$\mathrm{HCl}$ buffer. The specific activity of the resulting protein was $>12 \mathrm{nCi} / \mathrm{nmol}$. This procedure enabled us to obtain a labeled protein solution, free of contaminating low molecular weight radioactive components. Labeling was also performed at the laboratory of J.-P. Blein (INRA, Dijon, France) by a chemical method (Blein et al. 1991). Experiments performed with enzymatically and chemically labeled glycoprotein led to identical results. Radioactivity present in protein solutions or in the leaf tissue was quantified by $\gamma$-counting. Quantification of radioactivity on blots was performed with a model BAS 1000 analyzer (Fujix Bio-Imaging, Tokyo).

\section{RNA analysis.}

Total RNA was extracted from 0.5 to $1 \mathrm{~g}$ of plant material. Procedures for extraction and Northern hybridization have been described previously (Baillieul et al. 1995). The different probes used were as follows: the tobacco cDNA clones encoding PAL (Pellegrini et al. 1994), class II OMT (Pellegrini et al. 1993), PR-6 (Heitz et al. 1993), PR-8 (class III chitinase) (Stintzi et al. 1993a), PR-1, PR-3, and PR-5 provided by J. Bol (University of Leiden, The Netherlands) (Brederode et al. 1991). E. Jamet (IBMP, Strasbourg) provided us with a cDNA clone isolated from $N$. sylvestris and encoding HMGR (Genschick et al. 1992). A cDNA clone encoding the 25S rRNA from Capsicum annum obtained from R. Schantz (IBMP, Strasbourg) was used to normalize the RNA blots.

\section{Salicylic acid and scopoletin analysis.}

Extraction from leaf tissue and HPLC analysis of total salicylic acid are described in detail in Baillieul et al. (1995). For each time point, SA was extracted from leaves of three plants, representing 6 to 8 treated zones. Scopoletin was quantified by HPLC from the same SA samples and with the same HPLC conditions as for SA. Identification of scopoletin was assessed by comigration under the same HPLC conditions with commercial scopoletin and by comparison of the UV-visible spectra, using a diodearray detector (Waters, Milford, MA). Scans were performed from 205 to $420 \mathrm{~nm}$.

\section{ACKNOWLEDGEMENTS}

We thank E. Jamet, R. Schantz, and J. Bol for providing cDNAs clones; J.-P. Blein and L. Legendre for labeling the elicitor; P. Geoffroy for skillful technical assistance; B. Vivien for the help provided in $\gamma$ counting; M. Legrand for helpful discussions; and K. Richards for critical reading of the manuscript. This research was supported in part by grant no. 92-T-0200 from the French Ministry of Research. We acknowledge the financial support of M.-A. P. by Rhône Poulenc France.

\section{LITERATURE CITED}

Ahl-Goy, P., Signer, H., Reist, R., Aichholz, R., Blum, W., Schmidt, E., and Kessmann, H. 1993. Accumulation of scopoletin is associated with the high disease resistance of the hybrid Nicotiana glutinosa $\times$ Nicotiana debneyi. Planta 191:200-206.

Atkinson, M. M. 1993. Molecular mechanisms of pathogen recognition by plants. Adv. Plant Pathol. 10:35-64.

Baillieul, F., Fritig, B., and Kauffmann, S. 1996. Occurrence among Phytophthora species of a glycoprotein eliciting a hypersensitive response in tobacco and its relationships with elicitins. Mol. PlantMicrobe Interact. 9:214-216.

Baillieul, F., Genetet, I., Kopp, M., Saindrenan, P., Fritig, B., and Kauffmann, S. 1995. A new elicitor of the hypersensitive response in tobacco: A fungal glycoprotein elicits cell death, expression of defence genes, production of salicylic acid, and induction of systemic acquired resistance. Plant J. 8:551-560.

Baker, C. J., and Mock, N. M. 1994. An improved method for monitoring cell death in cell suspension and leaf disc assays using Evans blue. Plant Cell Tissue Organ. Cult. 39:7-12.

Bi, Y. M., Kenton, P., Darby, R., and Draper, J. 1995. Hydrogen peroxide does not function downstream of salicylic acid in the induction of PR protein expression. Plant J. 8:235-245.

Blein, J.-P., Millat, M.-L., and Ricci, P. 1991. Responses of cultured tobacco cells to cryptogein, a proteinaceous elicitor from Phytophthora cryptogea. Plant Physiol. 95:486-491.

Brederode, F. T., Linthorst, H. J. M., and Bol, J. F. 1991. Differential induction of acquired resistance and PR gene expression in tobacco by virus infection, ethephon treatment, UV light and wounding. Plant Mol. Biol. 17:1117-1125.

Collinge, D. B., and Slusarenko, A. J. 1987. Plant gene expression in response to pathogens. Plant Mol. Biol. 9:389-410.

Delaney, T. P., Ukness, S., Vernooij, B., Friedrich, L., Weymann, K., Negrotto, N., Gaffney, T., Gut-Rella, M., Kessmann, H., Ward, E., and Ryals, J. 1994. A central role of salicylic acid in plant disease resistance. Science 266:1247-1250.

Dixon, R. J., and Lamb, C. J. 1990. Molecular communication in interactions between plants and microbial pathogens. Annu. Rev. Plant Physiol. Plant Mol. Biol. 41:339-367.

Fritig, B., Hirth, L., and Ourisson, G. 1970. Biosynthesis of the coumarins: Scopoletin formation in tobacco tissue cultures. Phytochemistry 9:1963-1975.

Fritig, B., Legrand, M., and Hirth, L. 1972. Changes in the metabolism of phenolic compounds during the hypersensitive reaction of tobacco to TMV. Virology 47:845-848.

Gaffney, T., Friedrich, L., Vernooij, B., Negrotto, D., Nye, G., Uknes, S., Ward, E., Kessmann, H., and Ryals, J. 1993. Requirement of salicylic acid in systemic acquired resistance. Science 261:754-756.

Genschick, P., Criqui, M.-C., Parmentier, Y., Marbach, J., Durr, A., Fleck, J., and Jamet, E. 1992. Isolation and characterization of a cDNA encoding a 3-hydroxy-3-methylglutaryl coenzyme A reductase from Nicotiana sylvestris. Plant Mol. Biol. 20:337-341.

Heitz, T., Fritig, B., and Legrand, M. 1994. Local and systemic accumulation of pathogenesis-related proteins in tobacco plants infected with tobacco mosaic virus. Mol. Plant-Microbe Interact. 7:776-779.

Heitz, T., Geoffroy, P., Stintzi, A., Fritig, B., and Legrand, M. 1993. cDNA cloning and gene expression analysis of the microbial proteinase inhibitor of tobacco. J. Biol. Chem. 268:16987-16992.

Jones, A. M., and Dangl, J. L. 1996. Logjam at the Styx: Programmed cell death in plants. Trends Plant Sci. 1:114-119.

Keller, H., Bonnet, P., Galiana, E., Pruvot, L., Friedrich, L., Ryals, J., and Ricci, P. 1996. Salicylic acid mediates elicitin-induced systemic acquired resistance, but not necrosis in tobacco. Mol. Plant-Microbe Interact. 9:696-703.

Klement, Z. 1982. Hypersensitivity. Pages 149-177 in: Phytopathogenic prokaryotes. M. S. Mount and G. H. Lacy, eds. Academic Press, New York. 
Klessig, D. F., and Malamy, J. 1994. The salicylic acid signal in plants. Plant Mol. Biol. 26:1439-1458.

Kombrink, E., and Somssich, I. E. 1995. Defense responses of plants to pathogens. Adv. Bot. Res. 21:1-34.

Konate, G., Kopp, M., and Fritig, B. 1982. Multiplication du virus de la mosaïque du tabac dans des hôtes systémiques ou nécrotiques: Approche biochimique à l'étude de la résistance hypersensible aux virus. Phytopathol. Z. 105:214-225.

Lamb, C. J., Lawton, M. A., Dron, M., and Dixon, R. A. 1989. Signals and transduction mechanisms for activation of plant defenses against microbial attack. Cell 56:215-224.

Legrand, M. 1983. Phenylpropanoid metabolism and its regulation in disease. Pages 367-384 in: Biochemical Plant Pathology. J. A. Callow, ed. Wiley, Chichester, U.K.

Levine, A., Pennell, R. I., Alvarez, M. E., Palmer, R., and Lamb, C. 1996. Calcium-mediated apoptosis in a plant hypersensitive disease resistance response. Curr. Biol. 6:427-437.

Malamy, J., Carr, J., Klessig, D., and Raskin, I. 1990. Salicylic acid: A likely endogenous signal in the resistance response of tobacco to viral infection. Science 250:1002-1004.

Malamy, J., Sánchez-Casas, P., Hennig, J., Guo, A., and Klessig, D. F. 1996. Dissection of the salicylic acid signaling pathway in tobacco. Mol. Plant-Microbe Interact. 9:474-482.

Massala, R., Legrand, M., and Fritig, B. 1987. Comparative effects of two competitive inhibitors of phenylalanine ammonia-lyase on the hypersensitive resistance of tobacco to tobacco mosaic virus. Plant Physiol. Biochem. 25:217-225.

Meuwly, P., Mölders, W., Buchala, A., and Métraux, J. P. 1995. Local and systemic biosynthesis of salicylic acid in infected cucumber plants. Plant Physiol. 109:1107-1114.

Mölders, W., Buchala, A., and Métraux, J. P. 1996. Transport of salicylic acid in tobacco necrosis virus-infected cucumber plants. Plant Physiol. 112:787-792.

Mur, L. A. J., Naylor, G., Warner, S. A. J., Sugars, J. M., White, R. F., and Draper, J. 1996. Salicylic acid potentiates defense gene expression in tissue exhibiting acquired resistance to pathogen attack. Plant J. 9:559-571.

Pellegrini, L., Geoffroy, P., Fritig, B., and Legrand, M. 1993. Molecular cloning and expression of a new class of ortho-diphenol-O-methyltransferases induced in tobacco (Nicotiana tabacum L.) leaves by infection or elicitor treatment. Plant Physiol. 103:509-517.

Pellegrini, L., Rohfritsch, O., Fritig, B., and Legrand, M. 1994. Phenylalanine ammonia-lyase in tobacco. Molecular cloning and gene expression during the hypersensitive reaction to tobacco mosaic virus and the response to a fungal elicitor. Plant Physiol. 106:877-886.

Ricci, P., Bonnet, P., Huet, J.-C., Sallantin, M., Beauvais-Cante, F., Bruneteau, M., Billard, V., Michel, G., and Pernollet, J.-C. 1989. Structure and activity of proteins from pathogenic fungi Phytophthora eliciting necrosis and acquired resistance in tobacco. Eur. J. Biochem. 183:555-563.

Root, R. K., Metcalf, J., Oshino, N., and Chance, B. 1975. $\mathrm{H}_{2} \mathrm{O}_{2}$ release from human granulocytes during phagocytosis. J. Clin. Invest. 55: 945-955.

Ross, A. F. 1961a. Localized acquired resistance to plant virus infection in hypersensitive hosts. Virology 14:329-339.

Ross, A. F. 1961b. Systemic acquired resistance induced by localized virus infections in plants. Virology 14:340-358.

Stintzi, A., Geoffroy, P., Bersuder, D., Fritig, B., and Legrand, M. 1993a. cDNA cloning and expression studies of tobacco class III chitinaseslysozymes. Pages 312-315 in: Developments in Plant Pathology: Mechanisms of Plant Defense Responses. B. Fritig and M. Legrand, eds. Kluwer Academic Publishers, Dordrecht, The Netherlands.

Stintzi, A., Heitz, T., Prasad, V., Wiedemann-Merdinoglu, S., Kauffmann, S., Geoffroy, P., Legrand, M., and Fritig, B. 1993b. Plant "Pathogenesis-Related" proteins and their role in defense against pathogens. Biochimie 75:687-706.

Stoessl, A., Stothers, J. B., and Ward, E. W. B. 1976. Sesquiterpenoid stress compounds of the Solanaceae. Phytochemistry 15:855-872.

Ward, E., Uknes, S., Williams, S., Dincher, S., Wiederhold, D., Alexander, D., Ahl-Goy, P., Metraux, J. P., and Ryals, J. 1991. Coordinate gene activity in response to agents that induce systemic acquired resistance. Plant Cell 3:1085-1094.

Yalpani, N., Silvermann, P., Wilson, T. M. A., Kleier, D. A., and Raskin, I. 1991. Salicylic acid is a systemic signal and an inducer of pathogenesis-related proteins in virus-infected tobacco. Plant Cell 3:809818. 